\title{
Prevalence of Caesarean Section Deliveries Among Primigravidae in General Hospital Gboko, Benue State, Nigeria
}

\author{
Emmanuel Okechukwu Chukwu ${ }^{1}$, Chinasa Joy Ekeh ${ }^{2}$, Habu Haruna ${ }^{3}$, Terkuma Chia ${ }^{1}$, \\ Terna Mesuur Fiase ${ }^{1}$ \\ ${ }^{1}$ School of Nursing, Mkar, Gboko, Nigeria \\ ${ }^{2}$ School of Midwifery, Mkar, Gboko, Nigeria \\ ${ }^{3}$ Department of Nursing Science, College of Medical Sciences, University of Maiduguri, Nigeria
}

Email address:

emmanwaguy42@yahoo.com (E. O.Chukwu)

\section{To cite this article:}

Emmanuel Okechukwu Chukwu, Chinasa Joy Ekeh, Habu Haruna, Terkuma Chia, Terna Mesuur Fiase. Prevalence of Caesarean Section Deliveries Among Primigravidae in General Hospital Gboko, Benue State, Nigeria. International Journal of Clinical and Experimental Medical Sciences. Vol. 3, No. 5, 2017, pp. 61-65. doi: 10.11648/j.ijcems.20170305.12

Received: March 1, 2017; Accepted: March 21, 2017; Published: October 18, 2017

\begin{abstract}
The purpose of the study was to assess the prevalence of caesarean-section among primigravida in general hospital Gboko, Benue State, Nigeria. The study was a hospital-based cross-sectional retrospective survey conducted from January 2016-December 2016. The target population comprised all the primigravida within the age of 16-45 who underwent caesarean section in General Hospital Gboko, Benue State, Nigeria. The sample size consisted of 224 patients that met the inclusion criteria of caesarean deliveries performed after period of viability (28 weeks). Data collection instrument was the hospital delivery records from the maternity units, theatre records, admission and discharge registers in labour ward with outcome of caesarean section using delivery collection sheet. Collected data were analysed using frequency distribution table. Findings revealed increased incidence of caesarean section from a steep of $17.9 \%$ recorded in January-February after a rapid rise to $20.5 \%$ in September-October to $22.3 \%$ in November-December. Finding also showed that most of the cases of caesarean-section achieved a life viable fetus with an APGAR score of 8/10 in the first five minutes of life. Major indications for caesarean-section were due to failure to progress during labour, previous uterine scar, no reassuring fetal status and fetal mal-presentation. It was also revealed that majority of women who had a previous caesarean section ended up having a spontaneous vaginal delivery.
\end{abstract}

Keywords: Prevalence, Caeserean-Section, Deliveries, Among, Primigravidae, General Hospital, Nigeria

\section{Introduction}

A caesarean section is delivery of a fetus through a surgical incision in the abdominal wall; known as laparatomy, and an incision through the uterine wall known as hysterectomy [4]. This operation is intended to be used as a life-saving procedure for the mother and/or baby. However, a number of factors, such as the increasing labour induction rate, the option for women to choose an elective caesarean section and the decreasing option of vaginal birth after caesarean section for women have led to its over use in recent years.

The caesarean section rate is rising despite national goals to decrease their occurrence to $15 \%$ [13]. The United States has recorded the highest caesarean section rate ever, accounting for $26.1 \%$ of all deliveries in 2007 [8]. [3] states that the rising caesarean section rate can be correlated to the dramatic decrease in vaginal births after previous caesarean deliveries.

Across a population, the effects of caesarean section rates on maternal and newborn outcomes such as stillbirths or morbidities, birth asphyxia are still unknown. More research on the impact of caesarean section on woman's psychological and social well-being is still needed. Due to their increased cost, high rates of unnecessary caesarean sections can pull resources away from other services in overloaded and weak health systems. These conclusion highlights the value of 
caesarean section in saving the lives of mothers and new born says [11], Director of WHO's Department of Reproductive Health and Research.

The lack of standardized internationally accepted classification system to monitor and compare caesarean section rates in a constant and action oriented manner is one of the factors that has hindered a better understanding of this trend proposes adopting the Robson classification as an internationally applicable caesarean section classifications system. [3] classified all women admitted for delivery into one of 10 groups, based on characteristics that are easily identifiable, such as number of previous pregnancies, whether the baby comes head first, gestational age, previous uterine scars, number of babies, and how labour started. Using this system would facilitate comparison and analysis of caesarean rates within and between different facilities and across countries and regions.

\section{Objectives of the Study}

1. To determine the rate of caesarean section

2. To determine the pregnancy outcome of caesarean section

3. To ascertain the major indications and complications of caesarean section.

4. To know the possibilities of vaginal birth after caesarean section (VBACs).

\section{Methodology}

\subsection{Research Design}

Hospital based Cross-sectional retrospective study was conducted from 2016 - 2017 to determine the prevalence of primary caesarean section delivery in General Hospital Gboko, Gboko LGA of Benue State, Nigeria.

\subsection{Target Population}

The population of interest included all the primary caesarean section cases, especially primigravida who undergone $\mathrm{C}$-section within the age ranges of $16-45$ years.

\subsection{Sample Method}

Retrospective analysis of all the caesarean section carried out in General Hospital Gboko from January - December 2016. The obstetric theatre and labour ward records were reviewed to identify patients who underwent caesarean section during the study period.

\subsection{Data Collection Procedure}

The data for the study was collected using delivery data collection sheets which have socio-demographic variables, obstetric history and outcome of caesarean section. The collection sheet was prepared in English. Information was obtained from theatre records, labour ward records and neonatal ward records using a delivery data collection sheet.

\subsection{Inclusion Criteria}

Caesarean deliveries performed after period of viability (28 weeks), including elective, emergency, primary and repeat cases are included in the study.

\subsection{Exclusion Criteria}

Caesarean deliveries which lack full information

\subsection{Statistical Analysis}

The data collected was obtained by the researcher for this study. All the data collectors were registered nurses/midwives with backgrounds in obstetrics as well as labour and delivery. Collected data were compiled, organized and analyzed using frequencies distribution tables to describe some variables in order to express it as a statistic.

\subsection{Description of Data Collection Instrument}

The main instrument for data collection in this research was the delivery records from the maternity units, theatre records, admission and discharge registers in labour ward with outcome of caesarean section using delivery collection sheet with outcome of C-section and data of caesarean sections were all collected within the period of study to help gather an appropriate data for the study.

\section{Data Presentation and Discussion}

\subsection{Demographic Data of Respondents}

Table 1. Demographic data of respondent.

\begin{tabular}{|c|c|c|}
\hline Age of Patient & Number of Patients & Percentage (\%) \\
\hline $16-20$ & 15 & 6.7 \\
\hline $21-25$ & 25 & 11.2 \\
\hline $26-30$ & 98 & 43.8 \\
\hline $31-35$ & 74 & 33.0 \\
\hline $36+$ & 12 & 5.4 \\
\hline Total & 224 & 100 \\
\hline \multicolumn{3}{|l|}{ Marital Status } \\
\hline Married & 198 & 88.4 \\
\hline Single & 16 & 7.0 \\
\hline Divorced & 6 & 2.8 \\
\hline Widow & 4 & 1.8 \\
\hline Total & 224 & 100 \\
\hline \multicolumn{3}{|l|}{ Educational status } \\
\hline Primary school & 65 & 29.0 \\
\hline Secondary school & 70 & 31.2 \\
\hline Tertiary institution & 40 & 17.9 \\
\hline None of the above & 49 & 21.9 \\
\hline Total & 224 & 100 \\
\hline \multicolumn{3}{|l|}{ Occupation } \\
\hline Farming & 60 & 26.9 \\
\hline Trading & 76 & 33.9 \\
\hline Civil Servant & 85 & 37.9 \\
\hline Others & 3 & 1.3 \\
\hline Total & 224 & 100 \\
\hline \multicolumn{3}{|c|}{ Religious background } \\
\hline Christianity & 125 & 55.8 \\
\hline Islam & 64 & 28.6 \\
\hline
\end{tabular}




\begin{tabular}{lll}
\hline Age of Patient & Number of Patients & Percentage (\%) \\
\hline Paganism & 30 & 13.4 \\
Others & 5 & 2.2 \\
Total & 224 & 100 \\
\hline
\end{tabular}

The table 1 above shows the different age groups of patients, $6.7 \%$ falls within the age group of $16-20,11.2 \%$ falls within $21-25,43.8 \%$ falls within $26-30$ years, accounting for the highest age group that had caesarean section, $33.0 \%$ falls within $31-35,5.4 \%$ falls within those that are 36 years and above. The table also shows their marital status, $88.4 \%$ were married, $7 \%$ were single, $2.8 \%$ were divorced, $1.8 \%$ were widow. As per educational status, the table shows that caesarean section was more common in women with secondary school level education and accounts for $31.2 \%, 29 \%$ attended primary school level, $17.9 \%$ attended tertiary institution, $21.9 \%$ were unclassified group. On the occupation of the respondents, $26.9 \%$ were farmers, $33.9 \%$ were traders, $37.9 \%$ were civil servants, 1.3 were unclassified group. The table also show that $55.8 \%$ were Christians, $28.6 \%$ were Islams, $13.4 \%$ were Pagans, others $2.2 \%$.

\subsection{Prevalence of Caesarean-Section Among Primigravida}

Table 2. Showing the number of total deliveries and CS (\%).

\begin{tabular}{lll}
\hline Month & Total deliveries & CS (\%) \\
\hline January - February & 145 & $40(17.9)$ \\
March - April & 110 & $30(13.4)$ \\
May - June & 80 & $26(11.6)$ \\
July - August & 100 & $32(14.3)$ \\
September - October & 185 & $46(20.5)$ \\
November - December & 150 & $50(22.3)$ \\
Total & 770 & $224(100)$ \\
\hline
\end{tabular}

Table 2 above shows that there were increasing trend in caesarean section rates within the periods of research work, the increasing incidence of caesarean section on this center from a steep of $17.9 \%$ recorded in January- February (after a rapid rise to $20.5 \%$ in September to Octorber) to $22.3 \%$ in November to December. This finding is supported by that of [10] whose study found prevalence of caesarean section in their study population to be $21.40 \%$ out of 1149 pregancies been studied. Similar to the finding also is work of [1] whose study found prevalence of caesarean section to be $27.6 \%$ showing high incidence of caesarean section.

Table 3. Distribution of Caesarean section by antenatal care (ANC) follow up.

\begin{tabular}{lll}
\hline ANC follow up & No of CS & Percentage (\%) \\
\hline Yes & 158 & 70.5 \\
No & 66 & 29.5 \\
Total & 224 & 100 \\
\hline
\end{tabular}

Table 3 above shows that out of 224 patients that had caesarean section, $158(70.5 \%)$ of the women received regular antenatal care (ANC) in the hospital (booked), while the rest $66(29.5 \%)$ were unbooked. Among the booked patient of $158,148(69.5 \%)$ had emergency caesarean section while the remaining $10(10 \%)$ had elective caesarean section. $60(20.9 \%)$ of the unbooked patients had emergency $\mathrm{C} / \mathrm{S}$ while $6(9.0 \%)$ were done by elective C/S.

\subsection{Pregnancy Outcome After Caesarean Section}

Table 4. Pregnancy outcome of caesarean section.

\begin{tabular}{llll}
\hline Pregnancy Outcome & $\begin{array}{l}\text { Elective CS } \\
(\%)\end{array}$ & $\begin{array}{l}\text { Emergency CS } \\
(\%)\end{array}$ & Total \\
\hline Viable baby at birth & $45(20)$ & $120(53.7)$ & $165(73.7)$ \\
Asphyxiated baby & $10(4.5)$ & $35(15.6)$ & $45(20.1)$ \\
Still Birth & $4(1.8)$ & $6(2.7)$ & $10(4.5)$ \\
Maternal death & $1(0.4)$ & $3(1.3)$ & $4(1.7$ \\
& & & $224(100)$ \\
\hline
\end{tabular}

In table 4 above, viable babies were the major outcome of caesarean section, accounting for total number of 165 (73.7\%) with $53 \%$ of emergency CS, and $20 \%$ of elective CS, Asphyxiated babies were 45 (20.1\%) elective 4.5\%, emergency $15.6 \%$, still births were $10(4.5 \%)$ elective $1.8 \%$, emergency $2.7 \%$, maternal death $4(1.7 \%)$ elective were $0.4 \%$, emergency $(1.3 \%)$. Data also shows that most of the cases of caesarean section achieved a life viable fetus with an apgar score of $8 / 10$ in the first minutes of life. [7] states that birth by caesarean section was to save the lives of both the mother and the fetus. The purpose of their study was to develop a standardized methodology using richly available hospital data to identify indications for primary caesarean section and to ensure a positive outcome of each caesarean section procedure carried out. Similarly, [9] recommends that vaginal birth after $\mathrm{c} / \mathrm{s}$ is appropriate in most cases with proper fetal monitoring.

\subsection{Indications for Caesarean Section}

Table 5. Showing indications for caesarean section.

\begin{tabular}{lll}
\hline Indications & $\begin{array}{l}\text { Number of } \\
\text { patients }\end{array}$ & Percentage (\%) \\
\hline Previous C-section & 75 & 33.5 \\
Cephalopelvic disproportion & 65 & 29.0 \\
Foetal distress & 45 & 20.1 \\
Pregnancy induced hypertension & 15 & 6.6 \\
Obstructed labour & 10 & 4.5 \\
Ante partum haemorrhage & 10 & 4.5 \\
Others & 4 & 1.8 \\
Total & 224 & 100 \\
\hline
\end{tabular}

In the table 5 above, the major indication for caesarean section was previous caesarean section with percentage of 75 (33.5\%) followed by cephalopelvic disproportion with total of $65(29.0 \%)$ fetal distress accounted for $45(20.1 \%)$ followed by pregnancy induced hypertension 15 (6.6\%), obstructed labour were 10 (4.5\%), antepartum haemorrhage was also $10(4.5 \%)$, others which includes patients wish, aid obstetric history e t c were only 4 (1.8\%).

This shows that previous caesarean section was noticed as the commonest indication for caesarean section, followed by cephalopelvic disproportion. This finding is supported by that of [6] whose study showed major indications for caesarean 
section as follows: cephalopelvic disproportion (15.5\%), previous c/s (14.7\%), eclampsia (7.2\%), failed induction of labour $(5.5 \%)$ and placenta previa $(5.1 \%)$. Study by [14] also supports the finding. Their study showed that major includes maternal request $(28.43 \%)$, cephalopelvic dispropotion (14.08\%), fetal distress (12.46\%), previous c/s (10.25\%). [13] recommended that the urgency of caesarean section should be documented using the following standardized scheme in order to aid clear communication between healthcare professional, about the urgency of caesarean section immediate threat of the life of the women or fetus, no maternal or fetal compromise, delivery timed to suit women or staff.

Table 6. Maternal Complications of Elective and Emergency caesarean section and its percentage.

\begin{tabular}{llll}
\hline Complication & $\begin{array}{l}\text { Elective Cs } \\
(\mathbf{\%})\end{array}$ & $\begin{array}{l}\text { Emergency Cs } \\
\mathbf{( \% )}\end{array}$ & Total (\%) \\
\hline Anaemia & $17 .(17.5)$ & $45(45.4)$ & $62(63.9)$ \\
Pyrexia & $8(8.3)$ & $14 .(14.4)$ & $22(22.7)$ \\
Wound Infection & $4(4.1)$ & $5(5.2)$ & $9(9.3)$ \\
Thombo embolishm. & $1(1.0)$ & $3(3.1)$ & $4(4.1)$ \\
& & & $97(100)$ \\
\hline
\end{tabular}

In table 6 above, anaemia was the commonest complication accounting for $62(63.9 \%)$ of all the documented complications among all the women that had both elective and emergency caesarean section, both the booked and unbooked, followed by pyrexia $22(22.7 \%)$ and 9 women accounting for $9.3 \%$ had a wound infection. There were four cases of thromboembolism that occurred as operative complication accounting for a total of (4.1\%). 97 women in total had an operative complication and out of this women only 4 women died as a result of this complication. Two were caused by massive intraoperative haemorhage, one was due to pulmonary embolism, causing cardiac failure and the other was due to vulvular heart disease. Caesarean section is not without risk or complications for women, caesarean deliveries are potentially morbid procedures with over all infectious morbidity rates as high as $20 \%$ [2]; [12]. In addition to the increase risk of infection with caesarean section, women are exposed to complications such as excessive blood loss and damage to pelvic organ [3].

\subsection{Mode of Delivery After Having Caesarean Section}

Table 7. Mode of delivery following trial of vaginal birth after caesarean section.

\begin{tabular}{ll}
\hline Mode of delivery & No of cases \\
\hline Spontaneous vaginal delivery & 85 \\
Repeat lower segment CS & 15 \\
Vaginal instrumental delivery & 0 \\
Total & 100 \\
\hline
\end{tabular}

In table 7 above, out of the 224 sample used for the study, 100 cases were reviewed in the course of study as those who have had another delivery after the caesarean section, 85 women delivered vaginally, 15 had repeated lower segment caesarean section, while none passed through instrumental delivery. This shows that majority of women who had a previous caesarean section ended up having a spontaneous vaginal delivery. [15] Reported that the widespread of a policy whereby $80 \%$ of women with a prior caesarean section should have a VBAC would potentially eliminate up to one third of birth by caesarean section.

[12] Argued that the concerns around the safety of vaginal birth after caesarean section ignored the potential downstream consequences of a strategy whereby multiple elective repeat caesarean section are considered to be the safer option. It is also important to remember that pregnant women with both a previous caesarean section and a previous vaginal birth should be informed that they have an increase likelihood of achieving a vaginal birth than woman who have had a previous caesarean section but no previous vaginal birth. Many theories have tried to explain the upward trend of the number of caesarean section across the world. The explanation to this trend include; a decrease in VBAC, an increase in caesarean section performed for maternal request, changes in care provider practice patterns, increase number of high risk expectant mothers and obstetrical medico legal environment [10].

Table 8. Indication of previous caesarean section and outcome of trial of vaginal birth after caesarean section (VBAC) in present pregnancy.

\begin{tabular}{llll}
\hline Indication of Previous CS & $\begin{array}{l}\text { No of } \\
\text { cases }\end{array}$ & $\begin{array}{l}\text { Successful } \\
\text { VBAC }\end{array}$ & $\begin{array}{l}\text { Emergency } \\
\text { LSCS }\end{array}$ \\
\hline Fetal distress & 29 & 24 & 5 \\
Cephalopelvic disproportion & 20 & 17 & 3 \\
Breach presentation & 10 & 8 & 2 \\
Transverse presentation & 5 & 5 & - \\
Pre-eclampsia & 8 & 7 & 1 \\
Non progress of labour & 6 & 4 & 2 \\
Oligohydramnios & 5 & 4 & 1 \\
Prolonged PROM & 4 & 3 & 1 \\
Multiple Gestation & 3 & 3 & - \\
Postdatism & 2 & 2 & - \\
Cervical dystocia & 2 & 2 & - \\
Failure of induction & 1 & 1 & - \\
Unfavourable cervix & 1 & 1 & - \\
Cord prolapse & 4 & 4 & 15 \\
Total & 100 & 85 & - \\
\hline
\end{tabular}

VBAC-Vaginal Birth after Caesarean Section PROM-Premature Rupture of Membrance LSCS-Lower Segment Caesarean Section.

In table 8 above, the major indication of caesarean section were fetal distress accounting for $30 \%$, and outcome of VBAC was $25 \%$, cephalopelvic disproportion $20 \%$, VBAC was 17 e $\mathrm{t} c$, the result above showing that the success of vaginal birth after caesarean section was higher than LBCS.

\section{Conclusion}

A total of 770 women delivered during the study period, and among this women 224 underwent caesarean-section. The caesarean section prevalence was $29.1 \%$. Result showed that out of 224 c-section cases, 208 of them had emergency caesarean section while the remaining 16 cases had elective caesarean section. As far as various indications of $\mathrm{C}$-section are concerned, previous caesarean section was the most 
frequent indication $(33.5 \%)$, followed by cephalo-pelvic disproportion accounting for $29.0 \%$, and fetal distress $(20.1 \%)$, these were the leading causes of caesarean section. Result showed clearly that anemia was the major complication encountered as a result of the surgery.

\section{References}

[1] Ayano M., Beyene W. A. and Geremew M. A (2017) Prevalence and Outcome of Caesarean Section in Attat Hospital, Gurage Zone, SNNPR, Ethiopia. Archives of Medicine. Pubmed.

[2] Bashore G (2009) Health Consequences of the Increasing Caesarean Section Rates. Journal of epidemiology 18(4): 485486.

[3] Betran A. P., Merialdi M., Lauer J. A, Bing-Shun W., Thomas J., Van L. P, and Wagner M (2007) Rates of Caesarean Section: Analysis of Global, Regional and National Estimates. Paediatr Perinat Epidemiol 21(2): 98-113. Doi: 10.1111/j.1365-3016.2007.00786.x.

[4] Cunnuingham G., Gant S., Leveno B., Gilstrap F., and Wenstron G. (2008) Caesarean Section: The Definition. Lancet 368 (9546): 1472-1473.

[5] Gabay W. (2013) Reasons for Rising Caesarean Section Rate. Rev Obstet. Gynecol. 5(2): 69-77.

[6] Geidam A. D, Audu B. M., Kawuwa B. M. and Obed J. Y (2009) Rising Trend and Indications of Caeserean Section at the University of Maiduguri Teaching Hospital, Nigeria. Ann Afr Med 8 (2): 127-32. Doi: 10.4103/1596-3519.56242.
[7] Gregory E. (2012) Indications for Caesarean Section. BMC pregnancy childbirth: 14. 92.

[8] Hamilton A., Martin F. and Sullon G. (2007) Reason for Rising Trend of Caesarean Section Deliveryin Sri lanka. Journal of child Health. 40: 11-12.

[9] Landon M. B., and Grobman W. A (2017) Vaginal Birth after Caesarean delivery. $7^{\text {th }}$ edition. Philadelphia, P. A: Elsevier.

[10] Maimoona H., Asthma Y., Nazia B., Muhammad I. P., Nishat A., and Bushra G. (2014) revalence and Indications of Caesarean Section in a Teaching Hospital. JIMSA vol.27 No.1 P.15-16.

[11] Marleen T. (2012) The Value of Carrying out Caesarean Section to save both Mother and Baby. A Systematic Review: PLOS One 6 (1): e 14566.

[12] Penn Z. and Ghaem-Maghami S. (2001) Indications for Caesarean Section. Best Pract Res Clin Obstet Gynaecol 15(1): 1-15. doi: 10.1053/beog.2000.0146.

[13] Williams D. E. and Pridjian G. (2016) Textbook of Family Medicine. $9^{\text {th }}$ Edition. Philadelphia, P. A: Elsevier Saunders.

[14] Yajun L., Guanghui L., Yi C., Xin W., Yan R., Liying Z., and Weiyuan Z. (2014) A Descriptive Analysis of the Indications for Caesarean section in Mainland China. BMC Pregnacy and Childbirth 14: 410. doi: 10.1186/s12884-014-0410-2.

[15] Zied E. T and Sunna S. (2008) Practice Bulletin No 115. Vaginal birth after previous caesarean delivery. Obstet Gynecol 116: 450-463. 